\title{
REVIEW
}

\section{Immune plexins and semaphorins: old proteins, new immune functions}

\author{
Kelly Roney ${ }^{1^{*}}$, Eda Holl ${ }^{2^{*}}$, Jenny Ting ${ }^{3 \bowtie}$ \\ ${ }^{1}$ University of Chapel Hill, Department of Microbiology and Immunology, 22-004 Lineberger Comprehensive Cancer Center, \\ CB7295, Chapel Hill, NC 27599, USA \\ 2 Duke University, Department of Surgery, Durham, NC 27710, USA \\ ${ }^{3}$ University of Chapel Hill, Department of Microbiology and Immunology, 22-004 Lineberger Comprehensive Cancer Center, \\ CB7295, Chapel Hill, NC 27599, USA \\ $\square$ Correspondence: jenny_ting@med.unc.edu
}

Received October 23, 2012 Accepted October 25, 2012

\begin{abstract}
Plexins and semaphorins are a large family of proteins that are involved in cell movement and response. The importance of plexins and semaphorins has been emphasized by their discovery in many organ systems including the nervous (Nkyimbeng-Takwi and Chapoval, 2011; McCormick and Leipzig, 2012; Yaron and Sprinzak, 2012), epithelial (Miao et al., 1999; Fujii et al., 2002), and immune systems (Takamatsu and Kumanogoh, 2012) as well as diverse cell processes including angiogenesis (Serini et al., 2009; Sakurai et al., 2012), embryogenesis (Perala et al., 2012), and cancer (Potiron et al., 2009; Micucci et al., 2010). Plexins and semaphorins are transmembrane proteins that share a conserved extracellular semaphorin domain (Hota and Buck, 2012). The plexins and semaphorins are divided into four and eight subfamilies respectively based on their structural homology. Semaphorins are relatively small proteins containing the extracellular semaphorin domain and short intracellular tails. Plexins contain the semaphorin domain and long intracellular tails (Hota and Buck, 2012). The majority of plexin and semaphorin research has focused on the nervous system, particularly the developing nervous system, where these proteins are found to mediate many common neuronal cell processes including cell movement, cytoskeletal rearrangement, and signal transduction (Choi et al., 2008; Takamatsu et al., 2010). Their roles in the immune system are the focus of this review.
\end{abstract}

KEYWORDS plexin, semaphorin, immune system, dendritic cell, B cell, T cell

\section{DISCOVERY OF PLEXINS AND SEMAPHORINS}

A group of proteins that mediate cell movement was hypothesized by R.W. Sperry in his chemoaffinity hypothesis for nerve fiber growth (1963). This hypothesis was later supported by time lapse video of retinal ganglion growth fibers extending towards the optic tectum in Xenopus laevis embryos (Harris et al., 1987). Proteins thought to be involved in guidance were detected that same year in Xenopus optic tectum by monoclonal antibodies, which are today known to recognize plexin-A1 and neuropilin-1 (Takagi et al., 1987; Ohta et al., 1992; Fujisawa, 2004). The first semaphorin was identified as such in 1993 (Luo et al., 1993), and this led to the discovery of the semaphorin family based on homology of a common extracellular semaphorin domain (Luo et al., 1995). The semaphorin family was later expanded to include the semaphorin receptor proteins, plexins, which contain the 500 amino acid semaphorin domain as well as an additional intracellular plexin domain (Ohta et al., 1995; Satoda et al., 1995; Maestrini et al., 1996; Comeau et al., 1998). Currently at least 20 semaphorins and nine plexins have been identified.

The receptor and ligand pairs that mediate semaphorin and plexin signaling have been studied extensively. The receptor ligand pairing can vary by cell type, leading to difficulty in defining the receptor and ligand (Fig. 1). Plexins often serve as receptors for semaphorins, and are sometimes coupled with the co-receptor neuropilin (Janssen et al., 2010; Liu et al., 2010; Nogi et al., 2010). Additionally, the receptor

\footnotetext{
*These authors contributed equally to the work. 


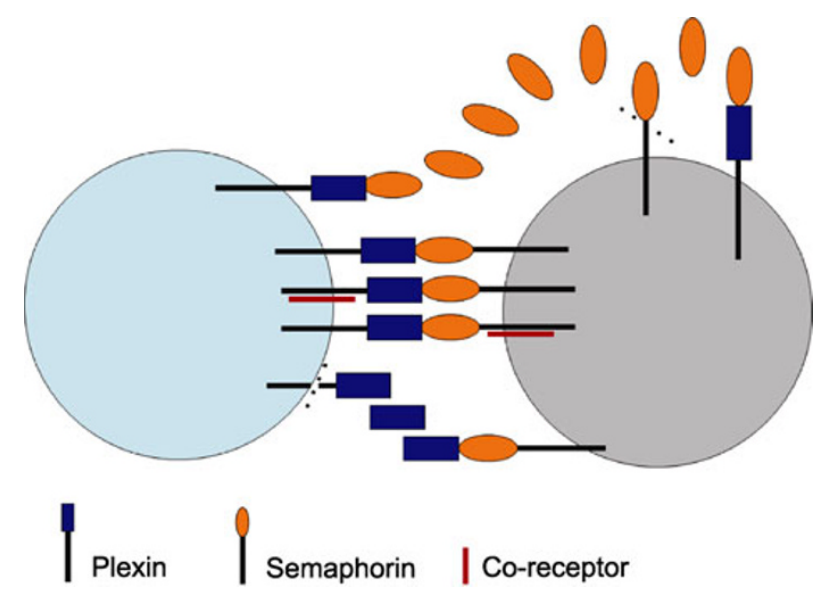

Figure 1. Plexins and semaphorin interactions. Plexins and semaphorins can be membrane bound or secreted and can act in a paracrine or autocrine manor. Plexin and semaphorin interactions can be facilitated or modified by co receptors.

ligand roles are dynamic due to the ability of both plexins and semaphorins to be membrane bound or secreted, transmit signals intra-cellularly, or bind to other types of proteins and form co-receptors. Semaphorin and plexin roles are further complicated by the ability of these proteins to act as either repulsive or attractive cues, with the type of signal depending on the receptor-ligand pair, developmental stage of the organism, cell type, and/or cellular context (Muratori and Tamagnone, 2012; Takamatsu and Kumanogoh, 2012; Yoshida, 2012).

\section{SEMAPHORINS}

All semaphorins contain the "sema domain", which consists of a variant form of the seven-blade beta-propeller fold, a highly conserved structure widely utilized for protein-protein interactions (Hota and Buck, 2012). Over 20 semaphorins have been identified and are categorized into groups based on their origin and sequence homology: invertebrate, vertebrate and viral semaphorins (1999). The invertebrate semaphorin group is further divided into two classes, I and II; whereas, the vertebrate semaphorins are divided into groups III-VII (Fig. 2). Class II, III, and VIII semaphorins are secreted
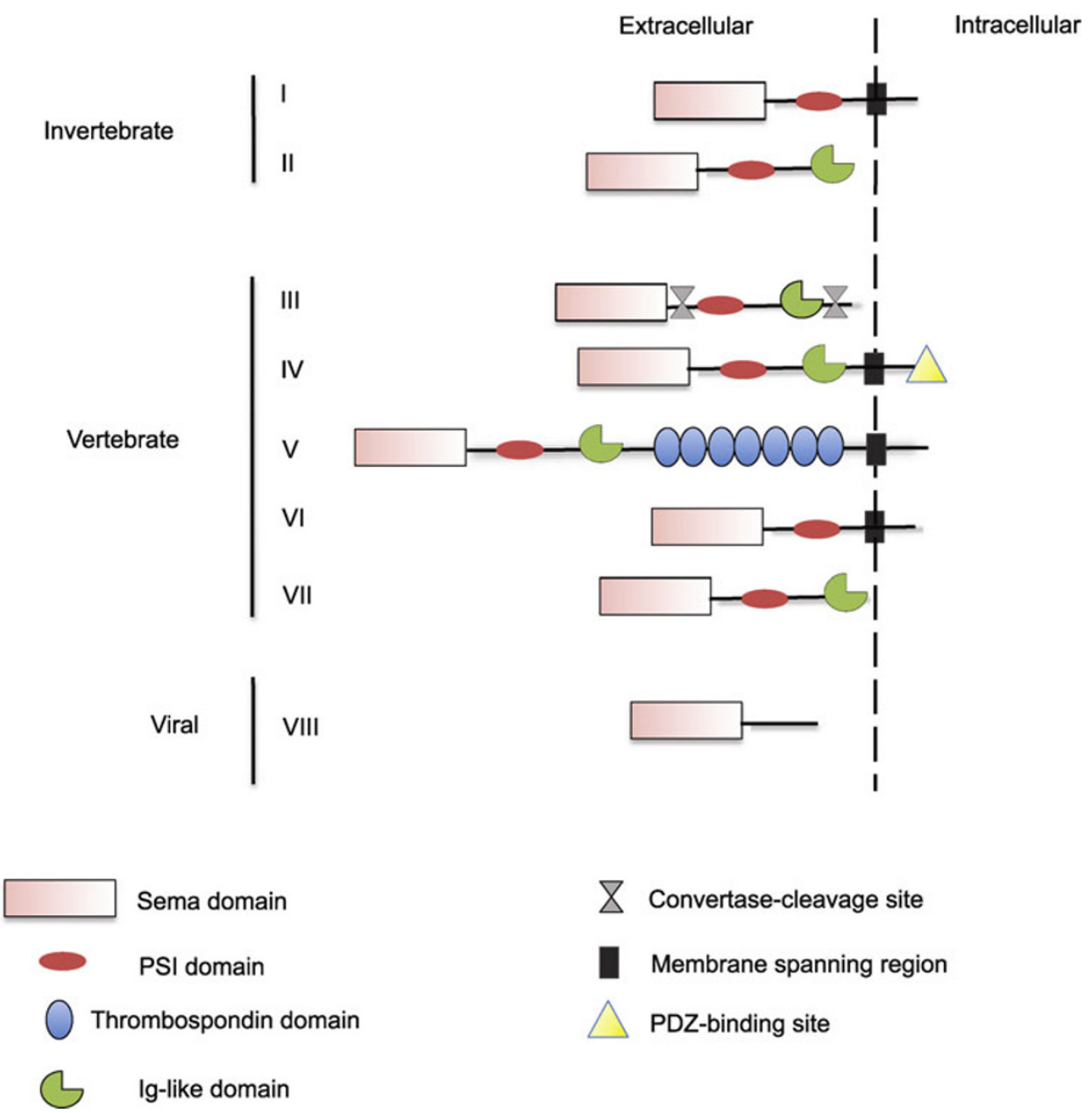

X Convertase-cleavage site

Membrane spanning region

PDZ-binding site

Figure 2. Semaphorins. There are eight classes of semaphorins. Classes I and II are found in invertebrates, classes III-VII are found in vertebrates and class VIII semaphorins are encoded by viruses. All semaphorins are characterized by sema domains which are followed by plexin semaphorin integrin (PSI), thrombospondin, and Ig-like domains. They can be either secreted or membrane-bound. 
whereas the rest are membrane bound (1999). Semaphorins range in size from 400-1000 amino acids, depending on the presence of additional domains, such as immunoglobulin (class II, III, IV, and VII) and thrombosponin domains (class V) or glycosylphosphatidylinositol (GPI) linkage sites (Mizui et al., 2009).

Semaphorins have two predominant classes of receptors; plexins and neuropilins (Zhou et al., 2008; Rizzolio and Tamagnone, 2011). Neuropilins are trans-membrane proteins ( 900 a.a.) which contain short intracellular domains and thus, lack intrinsic signaling capabilities (Takagi et al., 1991). Instead, neuropilins form co-receptor complexes with other cell surface molecules to mediate signal transduction (Kruger et al., 2005). The majority of semaphorins signal through plexins alone, however, class III semaphorins, with the exception of Sema3E, require neuropilin co-receptors to properly function (Gu et al., 2005; Chauvet et al., 2007). In addition to neuropilin and plexin receptors, semaphorins can signal through other receptors, such as CD72 and T-cell immunoglobulin and mucin domain-containing protein 2 (TIM-2) (Shi et al., 2000; Oinuma et al., 2004). It is clear that Semaphorins can transmit their signals through a series of receptors. Thus, it is expected that these multiple molecular interactions would lead to a variety of signal transductions, perhaps more complex than initially thought.

\section{PLEXINS}

Plexins are a conserved family of large proteins ( $200 \mathrm{kDa})$ that are the canonical receptors for semaphorin molecules
(Winberg et al., 1998; Takahashi et al., 1999). Like semaphorins, plexins can be soluble or membrane bound (Artigiani et al., 1999). Plexins are divided into four classes, A through D, based on their structural homology (Kruger et al., 2005). The invertebrate system contains two plexins, termed plexin-A and plexin-B. The vertebrate system contains four classes of plexins: class $A$ (Plexin-A1, A2, A3, A4), class B (Plexin-B1, B2, B3), class C (C1), and class D (D1) (Fig. 3).

Plexins are structurally homologous to receptor tyrosine kinases, MET and RON, which play important roles in development, tissue regeneration and cancer (Gherardi et al., 2004). The extracellular portion of plexin molecules contains a Sema domain, followed by three plexin-semaphorin-integrin (PSI) domains and three immunoglobulin, plexin and transcription factors (IPT) domains (Winberg et al., 1998; Bork et al., 1999; Antipenko et al., 2003). Sema domains are responsible for ligand binding in plexin, semaphorin, and the proto-oncogenic MET and RON receptor tyrosine kinases (Antipenko et al., 2003; Gherardi et al., 2004). In addition to its ligand-binding capabilities, the sema domain acts as an autoinhibitory element to restrict activation of plexin molecules (Takahashi and Strittmatter, 2001). For example, plexin-A1 mutants that lack the sema domain are constitutively active and nonresponsive to ligand stimulation (Takahashi and Strittmatter, 2001). Thus, the sema domains can be thought of as a regulatory element of plexin and semaphorin proteins that ensures proper activation.

The PSI domain has also been referred to as a small cystine-rich domain (CDR) or MET-related sequence and is

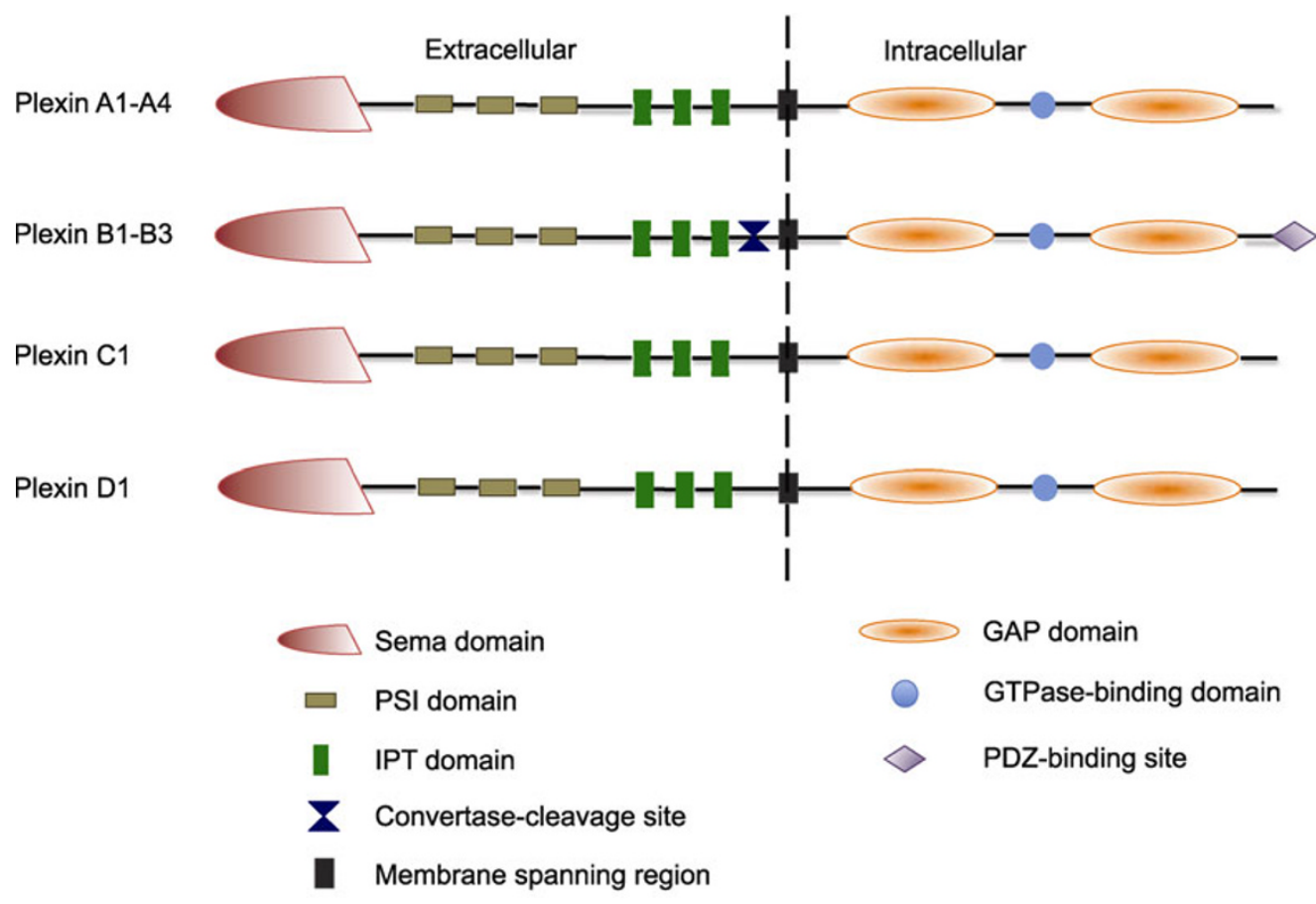

Figure 3. Plexins. Plexins are divided into four different groups, A-D, based on their origin and structural homology. Class $B$ plexins can be secreted whereas the rest of the plexins family members are membrane bound. 
required for proper protein-protein interactions (Ohta et al., 1995). Conclusions on the role of PSI domains in plexin interactions were mainly based on previous studies of Sema3A (Klostermann et al., 1998). Cystine-rich repeats of Sema3A are responsible for disulfide bond formation in the Sema3A homodimer (Klostermann et al., 1998). To date, evidence for the role of PSI domains in plexin molecules has been sparse.

IPT domains, also referred to as Ig domains or transcription factor Ig domains (TIG) are necessary for ligand binding (Aravind and Koonin, 1999). Studies blocking the IPT domain of the $\beta 2$ integrin have suggested that these domains are required for dimerization of the $\alpha \beta$ subunits (Huang et al., 1997). Other studies of MET proteins, lacking the sema domain, have revealed that the IPT domains alone are sufficient to ensure ligand binding (Basilico et al., 2008). Most of the research on plexin IPT domains has been done on plexin-A1 which showed that the absence of IPT domains inhibits association of this molecule with a triggering receptor on myeloid cells (TREM) family member and thus blocks downstream signaling (Watarai et al., 2008).

The cytoplasmic portion of plexin molecules is essential for signal transduction upon ligand binding but it does not exhibit kinase activity (Maestrini et al., 1996). The intracellular domain of plexins is highly conserved among all classes and it shares homology with the intracellular domain of p120 RasGAP (Rohm et al., 2000). Plexins contain a GTPase-binding domain and a segmented GTPase-activating protein (GAP) domain (Kruger et al., 2005). Many studies have focused on further elucidating the importance of plexin molecules in controlling GTPases (Rohm et al., 2000; Oinuma et al., 2004; Eun et al., 2006). These studies are of particular importance given the role of plexin molecules in cell movement, cy- toskeleton rearrangement and synapse formation (Torres-Vazquez et al., 2004; Eun et al., 2006).

In addition to all the components found in plexin molecules, plexin-B1 and B2 also contain convertase-cleavage sites (Winberg et al., 1998; Artigiani et al., 1999; Tamagnone et al., 1999). Cleavage and binding of these molecules to each other can result in formation of heterodimeric molecules with enhanced activity (Artigiani et al., 2003). Moreover, soluble plexin molecules can be released in the extracellular environment (Winberg et al., 1998; Artigiani et al., 1999; Tamagnone et al., 1999), thus, eliminating the need for cellular proximity during plexin-semaphorin signaling events.

\section{PLEXINS AND SEMAPHORINS IN THE IMMUNE SYSTEM}

Plexin and semaphorin signaling has gained much interest in field of immunology. Immune responses consist of a series of spatiotemporally regulated events that implicate a number of different immune cell types. During these events, immune cells interact with each other to modulate their course of action. Studies of plexins and semaphorins have revealed that several members of these families are involved in a series of immune cell interactions, which ultimately influence the outcome of the immune response. Here we present the current knowledge of semaphorin and plexin molecules in the immune system (also see Table 1).

\section{Semaphorin4D (Sema4D or CD100)}

Sema4D is the first semaphorin molecule to be reported in the immune system and is highly expressed by $T$ cells, mature DCs, and activated B cells (Delaire et al., 1998; Chen et

Table 1. Expression and activities of plexin and semaphorin family members in the immune system

\begin{tabular}{|c|c|c|c|}
\hline Plexin/semaphorin & Expression & Binding partner & Activities \\
\hline Plexin-A1 & DCs, plasmacytoid DCs & Semaphorin-6D, Semaphorin-3E & $\begin{array}{l}\text { DC activation, movement and lymph node } \\
\text { trafficking }\end{array}$ \\
\hline Plexin-A4 & T cells, DCs, Macrophages & Class 6 Semaphorins & $\begin{array}{l}\text { Inhibition of T cell activation } \\
\text { Enhancing TLR signaling }\end{array}$ \\
\hline Plexin-B1 & & Semaphorin-4D & \\
\hline Plexin-B2 & GC B cells, macrophages & $\begin{array}{l}\text { Semaphorin-4A } \\
\text { Semaphorin-4D }\end{array}$ & $\begin{array}{l}\text { Marks Germinal Centers, controls macro- } \\
\text { phage movement, } \gamma \delta T \text { cell activation }\end{array}$ \\
\hline Plexin-D1 & $\begin{array}{l}\text { Double positive thymocytes, } \\
\text { Activated B cells }\end{array}$ & Semaphorin- $4 \mathrm{~A}$ and $-3 \mathrm{E}$ & $\begin{array}{l}\text { Thymocyte trafficking } \\
\text { Germinal Center B cell development }\end{array}$ \\
\hline Semaphorin-3A & $\mathrm{T}$ cells & Plexin-A family & $\begin{array}{l}\text { Inhibits T-cell activation and monocyte migra- } \\
\text { tion, DC movement }\end{array}$ \\
\hline Semaphorin-3E & Thymic epithelial cells & Plexin D1 & $\begin{array}{l}\text { Double positive thymocyte migration and } \\
\text { movement, } T \text { cell development }\end{array}$ \\
\hline Semaphorin-4A & DCs, activated T cells, Th1 cells & Plexin-D1, Plexin-B2, Tim-2 & T-cell activation and monocyte migration \\
\hline Semaphorin-4D & T cells, activated B cells, DCs & CD72 & $\begin{array}{l}\text { B-cell activation and homeostasis, DC activa- } \\
\text { tion, mast cell responses }\end{array}$ \\
\hline Semaphorin-6D & T cells, B cells, NK cells & Plexin-A1 & $\begin{array}{l}\text { DC activation and production of type } 1 \text { inter- } \\
\text { feron, late-phase T cell proliferation }\end{array}$ \\
\hline Semaphorin-7A & Activated T cells & Integrin $\alpha 1 \beta 1$ & Monocyte/macrophage activation \\
\hline
\end{tabular}


al., 2000; Kumanogoh et al., 2000, 2002; Granziero et al., 2003; Kumanogoh et al., 2005). Sema4D has two known receptors, plexin-B1 and CD72, a C-type lectin (Huber et al., 2003; Zhou et al., 2008). The functional significance of Sema4D has been observed in both human and mouse immune systems. Initial studies of human Sema4D showed that this molecule promotes B-cell aggregation and differentiation (Hall et al., 1996). These studies were later confirmed in the mouse where over-expression of Sema4D enhanced CD40or LPS- induced proliferation and antibody production (Chen et al., 2000). Sema4D regulates B cell immune responses by mitigating CD72 inhibitory signals and thus allowing downstream BCR signaling to proceed (Adachi et al., 1998; Kumanogoh et al., 2000, 2005). The importance of Sema4D in B cell biology has been further demonstrated in studies utilizing Sema4D-deficient mice (Chen et al., 2000; Kumanogoh et al., 2005). In these studies, B cell homeostasis is altered in the absence of Sema4D. These mice exhibit reduced B-1 $B$ cell populations at a young age but increased numbers of marginal zone B cells later in life (Chen et al., 2000). Additionally, Sema $4 D^{-\digamma}$ mice exhibit impaired $\mathrm{T}$-dependent $(\mathrm{Td})$ antibody responses and priming of antigen specific $T$ cells.

Although $\mathrm{T}$ cells are the major Sema4D-producing cells in the immune system, Sema4D-deficient T cells develop normally and respond to antigenic stimuli (Chen et al., 2000). Other in vitro studies have shown that Sema4D recombinant protein is important in inducing expression of CD80 and CD86 co-stimulatory molecules on DCs (Kumanogoh et al., 2002), while antigen specific Sema $4 D^{-\digamma} \mathrm{T}$ cells do not differentiate into effector cells when cultured in the presence of DCs. Together these data suggest that Sema4D expression on $\mathrm{T}$ cells is important to promote $\mathrm{DC}$ activation and maturation, which in turn promotes $T$ cell activation (Kumanogoh et al., 2002). Further studies of human T and NK cells have demonstrated that the cytoplasmic domain of Sema4D interacts with a serine-threonine kinase (Elhabazi et al., 1997). Disease models of autoimmunity in Sema $4 D^{-\digamma}$ mice have revealed that this gene is important in controlling T-cell immune responses. Sema4D deficient mice are resistant to myelin oligodendrocyte glycoprotein (MOG) induced experimental autoimmune encephalomyelitis (EAE) (Ishida et al., 2003).

\section{Semaphorin4A (Sema4A) and TIM-2}

Sema4A is expressed on DCs and polarized T-helper type 1 (Th1) cells and is similar structurally to the above-described Sema4D (Kumanogoh et al., 2002). The only identified receptor for Sema4A in the immune system is the $T$ cell immunoglobulin and mucin domain-2 (TIM-2) receptor, a negative regulator of Th2 cells (Kumanogoh et al., 2002; Kuchroo et al., 2003; Chakravarti et al., 2005).

DC-derived Sema4A is required for adequate T-cell priming; however, Sema4A-deficient DCs develop normally and produce cytokines in response to various stimuli (Kumanogoh et al., 2005). T-cell derived Sema4A is required for helper $T$ cell differentiation (Th1) via T cell-T cell cognate interactions (Kumanogoh et al., 2005). Indeed, mice deficient in Sema4A exhibit impaired Th1 responses to heat-killed Propionibacterium acnes (Kumanogoh et al., 2005). However, these mice have enhanced responses to a Th2-inducing intestinal nematode, Nippostrongylus brasiliensis (Kumanogoh et al., 2005). These studies suggest a requirement for Sema4A in skewing of the $\mathrm{T}$ cell response towards a Th1 phenotype. Sema4 $A^{-/}$ mice show attenuated development of experimental autoimmune myocarditis, thus, further emphasizing the importance of this molecule in immune responses (Makino et al., 2008). Additionally, Sema $4 A^{-\digamma}$ mice on a BALB/c background are more prone to Th2 responses and develop spontaneous atopic dermatitis (Fujisawa et al.).

\section{Plexin-A1, semaphorin6D (Sema6D), and semaphorin 3A (Sema3A)}

Sema6D is expressed on T, B and NK cells (Takegahara et al., 2006). Plexin-A1 is a well-studied receptor for Sema6D (Yoshida et al., 2006) and was initially shown to be one of the gene products induced by CIITA (Wong et al., 2003). Plexin-A1 is highly expressed by mature DCs but is low to undetectable in other immune cell types, such as macrophages, B cells and T cells (Wong et al., 2003; Takamatsu et al., 2010). Short hairpin RNA knock down studies demonstrated the functional significance of plexin-A1 in DC biology (Wong et al., 2003). DCs that lack expression of plexin-A1 have a reduced capacity to activate $T$ cells both in vitro and in vivo. These findings were confirmed in studies of Plxna1 ${ }^{-/}$ mice (Takegahara et al., 2006; Takamatsu et al., 2010). In addition, plexin-A1 associates with a molecular complex consisting of i) the triggering receptors expressed on myeloid cells-2 (TREM-2) and ii) the immuno-receptors tyrosine-based activation motif (ITAM)-bearing adaptor protein (DAP12). DCs deficient in TREM-2 or DAP12 behave similarly to plexnA1 deficient DCs (Takegahara et al., 2006), indicating that these adaptor molecules are important mediators of Sema6D-induced plexin-A1 signaling.

Plexin molecules can impact the onset of autoimmune diseases (Kumanogoh et al., 2002; Tamura et al., 2008). Plxna1 ${ }^{-\leftarrow}$ mice are resistant to MOG-induced EAE (Takegahara et al., 2006). In part, the generation of MOG-specific T cells is abrogated in plexin-A1-deficient DCs mitigating the induction of EAE upon exposure to MOG antigen. In addition, Sema6D has been implicated in the late phase of T-cell responses (O'Connor et al., 2008) as CD4 T cells initiate expression of Sema6D by day4 post activation. Blocking Sema6D leads to decreased T-cell proliferation and inhibition of CD127 (IL-7 receptor) expression on $\mathrm{T}$ cells (O'Connor et al., 2008). Taken together these studies suggest that Sema6D and plexin-A1 partnering and signaling are likely to be implicated in regulation of late phases of T-cell 
immune responses and ultimately in generation of immunological memory.

Recent studies have focused on the interaction of plexin-A1 and Sema3A as regulators of dendritic cells movement into the lymphatics by activating myosin-II, thus, demonstrating a different role of plexin-A1 when partnering with a Semaphorin different from Sema6D (Takamatsu et al., 2010). Although, the work focusing on Sema3A in humans has been limited, recent studies have shown that this molecule is involved in macrophage differentiation as well as apoptosis $(\mathrm{Ji}$ et al., 2009). Taken together these studies emphasize the importance of plexins and semaphorins in cell movement, differentiation and apoptosis across different species.

\section{Semaphorin7A (Sema7A), $\alpha 1 \beta 1$ integrin and plexin-C1}

Sema7A is a GPI-anchored protein expressed by $\mathrm{CD} 4^{+} \mathrm{CD} 8^{+}$ double positive thymocytes and activated $T$ cells (Baker, 2009). Plexin-C1 and $\alpha 1 \beta 1$ integrin are two known receptors for Sema7A, (Pasterkamp and Kolodkin, 2003; Suzuki et al., 2007). Activated T cells that express Sema7A can stimulate monocytes/macrophages through $\alpha 1 \beta 1$ integrin, inducing proinflammatory cytokine production (Suzuki et al., 2007). Sema $7 A^{-\alpha}$ mice are resistant to inflammatory diseases such as hapten-induced contact hypersensitivity and EAE (Suzuki et al., 2007). In addition, Sema7A plays a critical role in TGF- $\beta 1$-induced fibrosis, myofibroblast hyperplasia alveolar remodeling, and apoptosis (Hur et al., 2008). These studies indicate that Sema7A is important in regulating inflammatory immune responses.

\section{Semaphorin6A (Sema6A), semaphorin 3A (Sema3A), and plexin-A4}

Plexin-A4 is expressed by $\mathrm{T}$ cells, DCs, and macrophages (Tamura et al., 2008) and interacts with at least two receptors, Sema3A and Sema6A (Suto et al., 2007). Plxna4 ${ }^{-\gamma}$ mice exhibit enhanced T-cell priming and exacerbated EAE disease; however, the mechanism by which plexin-A4 exerts its functions on T cells remains unknown (Tamura et al., 2008).

Our own work showed the important role of plexin-A4 in Toll-like receptor function in macrophages (Wen et al., 2010). Plexin-A4 is highly expressed by peripheral macrophages and DC. By studying Plxna4 ${ }^{-\digamma}$ innate immune cells, we showed that this protein is not involved in phagocytosis or antigen presentation but it is important in TLR signaling. Plxna ${ }^{-\digamma}$ cells showed reduced cytokine production upon activation by TLR2, 3, 4, 7, and 9 agonists and by bacteria. It turns out plexin-A4 is necessary for the activation of the small guanosine triphosphate hydrolase (GTPase) Rac1 (ras-related C3 botulinum toxin substrate 1), which is necessary for TLR activation. In accordance with this, Plxna4 ${ }^{--}$ mice were resistant to endotoxin shock and sepsis-associated cytokine storm. The ligand in this process was identified as Sema3A, which expression is enhanced by toll-like receptors, thus completing an autocrine loop of inflammation. Thus it might be possible to interfere with plexin-A4 and Sema3A signaling in treating sepsis and a cytokine storm, diseases which have been not had much therapeutic options.

\section{Plexin-B1, plexin-B2 and Sema4D}

The B plexin family shows the highest homology to the scatter factor receptor family, which is a family of transmembrane receptors that lead to invasive growth and are often linked to cancer (Maestrini, Tamagnone et al. 1996; Conrotto, Corso et al. 2004). Plexin-B1 is found on immature bone marrow derived dendritic cells but not on mature dendritic cells or monocytes (Chabbert-de Ponnat, Marie-Cardine et al. 2005). Plexin-B1 has also been identified on microglia and lung dendritic cells (Toguchi 2009, (Smith et al., 2011). In immature dendritic cells, soluble Sema4D, a ligand for Plexin-B1, inhibits migration, and this inhibition can be blocked by antibody against Plexin-B1 (Chabbert-de Ponnat, Marie-Cardine et al. 2005). Plexin-B1 is also expressed on bone marrow stromal cells, activated $T$ cells, and follicular dendritic cells (Granziero et al., 2003). Ligation of Sema4D on B cells by Plexin-B1 induces increased B-cell proliferation and longer B cell lifespan (Granziero, Circosta et al. 2003). Binding of soluble CD100 to plexin B1 on immature dendritic cells inhibits migration of the immature DCs (Chabbert-de Ponnat et al., 2005). In the kidney, plexin-B1 expression on glomeruli facilitates the recruitment of macrophages expressing Sema4D. Sema4D activates microglia through plexin-B1, and transfer of myelin oligodendrocyte glycoprotein-specific $T$ cells into Plxnb1 ${ }^{-\leftarrow}$ mice results in attenuated experimental autoimmune encephalomyelitis (Okuno et al., 2010).

Plexin-B2 is upregulated in T-dependent but not T-independent germinal centers (Yu et al., 2008). However the biological function of the upregulation of plexin-B2 in germinal centers has not yet been elucidated. Our group has shown that plexin-B2 is expressed on macrophages, dendritic cells, and plasmacytoid dendritic cells (Roney et al., 2011). Macrophages deficient in PIxnb2 have greater cell motility, more of the active form of the Rho family proteins Rac and Cdc42, and are faster at wound closure in-vitro (Roney et al., 2011). The level of plexin-B2 expressed on peritoneal F4/80+ macrophages is increased after thioglycollate treatment in a mouse model of peritonitis (Meda et al., 2012). Our group has demonstrated that dendritic cells deficient in plexin-B2 express higher levels of IL-12/IL-23p40 (Holl, Roney et al. 2012). Plexin-B2 has been identified on keratinocytes, where it interacts with Sema4D on $y \delta$ T cells and is required for $y \delta T$ cell activation (Witherden et al., 2012).

\section{Plexin-D1, semaphorin3E and semaphorin4A}

Initially, plexin-D1 was identified for its key role in vasculature development (Gitler et al., 2004; Asselin-Paturel et al., 2005). 
Plxnd1 $1^{-/}$mice suffer congenital heart defects due to improper vessel patterning (Gitler et al., 2004; Asselin-Paturel et al., 2005). Plexin-D1 is expressed by $C D 4^{+} C D 8^{+}$"double positive" (DP) thymocytes and plexin-D1 has been shown to interact with Sema3E (Bark et al., 2008; Ji et al., 2009) but not Sema4A (Toyofuku et al., 2007). Plxnd1 ${ }^{-\leftarrow}$ DP thymocytes are arrested in the cortex and seldom travel to the medulla (Choi et al., 2008). Recent studies from our laboratory have shown a role for plexin-D1 in B-cell biology (Holl et al., 2011). Plexin-D1 is important in controlling germinal center formation and long-term B cell immune responses. Our laboratory showed that plexin-D1 is expressed by DCs and its absence results in increased IL-12p40 cytokine production (Holl, Roney et al. 2012). Studies have demonstrated that plexin-D1 and its ligand Sema4A are expressed on macrophages and macrophage migration towards Sema4A is abrogated in the presence of plexin-D1 blocking antibody (Meda et al., 2012). Future studies on the plexin-D1 gene may provide additional options in vaccine development.

\section{CONCLUSIONS}

Plexins and semaphorins mediate many cell processes critical to the immune system including cell-cell contact, migration, and cytokine secretion. As described above, plexins and semaphorins are a new class of immunoregulatory molecules with distinct functions in various phases of the immune response. The effects of plexins and semaphorins are contextand cell differentiation state-dependent and many have complex influences in the immune system as a whole. Several plexins and semaphorins are important in maintaining immunological homeostasis. Lack of these molecules can result in attenuated immune responses. Alternatively, several of these molecules are required to prevent autoimmune disorders. Despite this body of knowledge on the role of plexins and semaphorins in the immune system is underappreciated for its broad implication.

\section{ABBREVIATIONS}

CDR, cystine-rich domain; GAP, GTPase-activating protein; GPI, glycosylphosphatidylinositol; ITAM, immuno-receptors tyrosinebased activation motif; PSI, plexin semaphorin integrin; TIM-2, T-cell immunoglobulin and mucin domain-containing protein 2; TREM, triggering receptor on myeloid cell

\section{REFERENCES}

(1999). Unified nomenclature for the semaphorins/collapsins. Semaphorin Nomenclature Committee. Cell 97, 551-552.

Adachi, T., Flaswinkel, H., Yakura, H., Reth, M., and Tsubata, T. (1998). The B cell surface protein CD72 recruits the tyrosine phosphatase SHP-1 upon tyrosine phosphorylation. J Immunol 160, 4662-4665.

Antipenko, A., Himanen, J.P., van Leyen, K., Nardi-Dei, V., Lesniak, J., Barton, W.A., Rajashankar, K.R., Lu, M., Hoemme, C., Puschel, A.W., et al. (2003). Structure of the semaphorin-3A receptor binding module. Neuron 39, 589-598.
Aravind, L., and Koonin, E.V. (1999). Gleaning non-trivial structural, functional and evolutionary information about proteins by iterative database searches. J Mol Biol 287, 1023-1040.

Artigiani, S., Barberis, D., Fazzari, P., Longati, P., Angelini, P., van de Loo, J.W., Comoglio, P.M., and Tamagnone, L. (2003). Functional regulation of semaphorin receptors by proprotein convertases. J Biol Chem 278, 10094-10101.

Artigiani, S., Comoglio, P.M., and Tamagnone, L. (1999). Plexins, semaphorins, and scatter factor receptors: a common root for cell guidance signals? IUBMB Life 48, 477-482.

Asselin-Paturel, C., Brizard, G., Chemin, K., Boonstra, A., O'Garra, A., Vicari, A., and Trinchieri, G. (2005). Type I interferon dependence of plasmacytoid dendritic cell activation and migration. The Journal of experimental medicine 201, 1157-1167.

Baker, J.R., Jr. (2009). Dendrimer-based nanoparticles for cancer therapy. Hematology Am Soc Hematol Educ Program, 708-719.

Bark, H., Xu, H.D., Kim, S.H., Yun, J., and Choi, C.H. (2008). P-glycoprotein down-regulates expression of breast cancer resistance protein in a drug-free state. FEBS Lett 582, 2595-2600.

Basilico, C., Arnesano, A., Galluzzo, M., Comoglio, P.M., and Michieli, P. (2008). A high affinity hepatocyte growth factor-binding site in the immunoglobulin-like region of Met. J Biol Chem 283, 21267-21277.

Bork, P., Doerks, T., Springer, T.A., and Snel, B. (1999). Domains in plexins: links to integrins and transcription factors. Trends Biochem Sci 24, 261-263.

Chabbert-de Ponnat, I., Marie-Cardine, A., Pasterkamp, R.J., Schiavon, V., Tamagnone, L., Thomasset, N., Bensussan, A., and Boumsell, L. (2005). Soluble CD100 functions on human monocytes and immature dendritic cells require plexin $\mathrm{C} 1$ and plexin B1, respectively. Int Immunol 17, 439-447.

Chakravarti, S., Sabatos, C.A., Xiao, S., Illes, Z., Cha, E.K., Sobel, R.A., Zheng, X.X., Strom, T.B., and Kuchroo, V.K. (2005). Tim-2 regulates $T$ helper type 2 responses and autoimmunity. J Exp Med 202, 437-444.

Chauvet, S., Cohen, S., Yoshida, Y., Fekrane, L., Livet, J., Gayet, O., Segu, L., Buhot, M.C., Jessell, T.M., Henderson, C.E., et al. (2007). Gating of Sema3E/PlexinD1 signaling by neuropilin-1 switches axonal repulsion to attraction during brain development. Neuron 56, 807-822.

Chen, Z., Koralov, S.B., Gendelman, M., Carroll, M.C., and Kelsoe, G. (2000). Humoral immune responses in Cr2-/- mice: enhanced affinity maturation but impaired antibody persistence. J Immunol 164, 4522-4532.

Choi, Y.I., Duke-Cohan, J.S., Ahmed, W.B., Handley, M.A., Mann, F., Epstein, J.A., Clayton, L.K., and Reinherz, E.L. (2008). PlexinD1 glycoprotein controls migration of positively selected thymocytes into the medulla. Immunity 29, 888-898.

Comeau, M.R., Johnson, R., DuBose, R.F., Petersen, M., Gearing, P., VandenBos, T., Park, L., Farrah, T., Buller, R.M., Cohen, J.I., et al. (1998). A poxvirus-encoded semaphorin induces cytokine production from monocytes and binds to a novel cellular semaphorin receptor, VESPR. Immunity 8, 473-482.

Delaire, S., Elhabazi, A., Bensussan, A., and Boumsell, L. (1998). CD100 is a leukocyte semaphorin. Cell Mol Life Sci 54, 1265-1276.

Elhabazi, A., Lang, V., Herold, C., Freeman, G.J., Bensussan, A., 
Boumsell, L., and Bismuth, G. (1997). The human semaphorin-like leukocyte cell surface molecule CD100 associates with a serine kinase activity. J Biol Chem 272, 23515-23520.

Eun, S.Y., O'Connor, B.P., Wong, A.W., van Deventer, H.W., Taxman, D.J., Reed, W., Li, P., Blum, J.S., McKinnon, K.P., and Ting, J.P. (2006). Cutting edge: rho activation and actin polarization are dependent on plexin-A1 in dendritic cells. J Immunol 177, 4271-4275.

Fujii, T., Nakao, F., Shibata, Y., Shioi, G., Kodama, E., Fujisawa, H., and Takagi, S. (2002). Caenorhabditis elegans PlexinA, PLX-1, interacts with transmembrane semaphorins and regulates epidermal morphogenesis. Development 129, 2053-2063.

Fujisawa, H. (2004). Discovery of semaphorin receptors, neuropilin and plexin, and their functions in neural development. J Neurobiol $59,24-33$.

Fujisawa, H., Ohtsuki, T., Takagi, S., and Tsuji, T. (1989). An aberrant retinal pathway and visual centers in Xenopus tadpoles share a common cell surface molecule, A5 antigen. Dev Biol 135, 231-240.

Gherardi, E., Love, C.A., Esnouf, R.M., and Jones, E.Y. (2004). The sema domain. Curr Opin Struct Biol 14, 669-678.

Gitler, A.D., Lu, M.M., and Epstein, J.A. (2004). PlexinD1 and semaphorin signaling are required in endothelial cells for cardiovascular development. Dev Cell 7, 107-116.

Granziero, L., Circosta, P., Scielzo, C., Frisaldi, E., Stella, S., Geuna, M., Giordano, S., Ghia, P., and Caligaris-Cappio, F. (2003). CD100/Plexin-B1 interactions sustain proliferation and survival of normal and leukemic CD5+ B lymphocytes. Blood 101, 1962-1969.

Gu, C., Yoshida, Y., Livet, J., Reimert, D.V., Mann, F., Merte, J., Henderson, C.E., Jessell, T.M., Kolodkin, A.L., and Ginty, D.D. (2005). Semaphorin 3E and plexin-D1 control vascular pattern independently of neuropilins. Science 307, 265-268.

Hall, K.T., Boumsell, L., Schultze, J.L., Boussiotis, V.A., Dorfman, D.M., Cardoso, A.A., Bensussan, A., Nadler, L.M., and Freeman, G.J. (1996). Human CD100, a novel leukocyte semaphorin that promotes B-cell aggregation and differentiation. Proc Natl Acad Sci U S A 93, 11780-11785.

Harris, W.A., Holt, C.E., and Bonhoeffer, F. (1987). Retinal axons with and without their somata, growing to and arborizing in the tectum of Xenopus embryos: a time-lapse video study of single fibres in vivo. Development 101, 123-133.

Holl, E.K., O'Connor, B.P., Holl, T.M., Roney, K.E., Zimmermann, A.G., Jha, S., Kelsoe, G., and Ting, J.P. (2011). Plexin-D1 is a novel regulator of germinal centers and humoral immune responses. J Immunol 186, 5603-5611.

Hota, P.K., and Buck, M. (2012). Plexin structures are coming: opportunities for multilevel investigations of semaphorin guidance receptors, their cell signaling mechanisms, and functions. Cell Mol Life Sci 69, 2765-3805.

Huang, C., Lu, C., and Springer, T.A. (1997). Folding of the conserved domain but not of flanking regions in the integrin beta2 subunit requires association with the alpha subunit. Proc Natl Acad Sci U S A 94, 3156-3161.

Huber, A.B., Kolodkin, A.L., Ginty, D.D., and Cloutier, J.F. (2003). Signaling at the growth cone: ligand-receptor complexes and the control of axon growth and guidance. Annu Rev Neurosci 26, 509-563.

Hur, E.H., Lee, J.H., Lee, M.J., Choi, S.J., Kang, M.J., Seol, M., Jang, Y.E., Lee, H.J., Kang, I.S., Shim, S.K., et al. (2008). C3435T polymorphism of the MDR1 gene is not associated with P-glycoprotein function of leukemic blasts and clinical outcome in patients with acute myeloid leukemia. Leuk Res 32, 1601-1604.

Ishida, I., Kumanogoh, A., Suzuki, K., Akahani, S., Noda, K., and Kikutani, H. (2003). Involvement of CD100, a lymphocyte semaphorin, in the activation of the human immune system via CD72: implications for the regulation of immune and inflammatory responses. Int Immunol 15, 1027-1034.

Janssen, B.J., Robinson, R.A., Perez-Branguli, F., Bell, C.H., Mitchell, K.J., Siebold, C., and Jones, E.Y. (2010). Structural basis of semaphorin-plexin signalling. Nature 467, 1118-1122.

Ji, J.D., Park-Min, K.H., and Ivashkiv, L.B. (2009). Expression and function of semaphorin $3 A$ and its receptors in human monocyte-derived macrophages. Human Immunol 70, 211-217.

Klostermann, A., Lohrum, M., Adams, R.H., and Puschel, A.W. (1998). The chemorepulsive activity of the axonal guidance signal semaphorin D requires dimerization. J Biol Chem 273, 7326-7331.

Kruger, R.P., Aurandt, J., and Guan, K.L. (2005). Semaphorins command cells to move. Nat Rev Mol Cell Biol 6, 789-800.

Kuchroo, V.K., Umetsu, D.T., DeKruyff, R.H., and Freeman, G.J. (2003). The TIM gene family: emerging roles in immunity and disease. Nature reviews. Immunology 3, 454-462.

Kumanogoh, A., Marukawa, S., Suzuki, K., Takegahara, N., Watanabe, C., Ch'ng, E., Ishida, I., Fujimura, H., Sakoda, S., Yoshida, K., et al. (2002). Class IV semaphorin Sema4A enhances T-cell activation and interacts with Tim-2. Nature 419, 629-633.

Kumanogoh, A., Shikina, T., Suzuki, K., Uematsu, S., Yukawa, K., Kashiwamura, S., Tsutsui, H., Yamamoto, M., Takamatsu, H., Ko-Mitamura, E.P., et al. (2005). Nonredundant roles of Sema4A in the immune system: defective $\mathrm{T}$ cell priming and Th1/Th2 regulation in Sema4A-deficient mice. Immunity 22, 305-316.

Kumanogoh, A., Watanabe, C., Lee, I., Wang, X., Shi, W., Araki, H., Hirata, H., Iwahori, K., Uchida, J., Yasui, T., et al. (2000). Identification of CD72 as a lymphocyte receptor for the class IV semaphorin CD100: a novel mechanism for regulating $B$ cell signaling. Immunity 13, 621-631.

Liu, H., Juo, Z.S., Shim, A.H., Focia, P.J., Chen, X., Garcia, K.C., and $\mathrm{He}, X$. (2010). Structural basis of semaphorin-plexin recognition and viral mimicry from Sema7A and A39R complexes with PlexinC1. Cell 142, 749-761.

Luo, Y., Raible, D., and Raper, J.A. (1993). Collapsin: a protein in brain that induces the collapse and paralysis of neuronal growth cones. Cell 75, 217-227.

Luo, Y., Shepherd, I., Li, J., Renzi, M.J., Chang, S., and Raper, J.A. (1995). A family of molecules related to collapsin in the embryonic chick nervous system. Neuron 14, 1131-1140.

Maestrini, E., Tamagnone, L., Longati, P., Cremona, O., Gulisano, M., Bione, S., Tamanini, F., Neel, B.G., Toniolo, D., and Comoglio, P.M. (1996). A family of transmembrane proteins with homology to the MET-hepatocyte growth factor receptor. Proc Natl Acad Sci U S A 93, 674-678. 
Makino, N., Toyofuku, T., Takegahara, N., Takamatsu, H., Okuno, T., Nakagawa, Y., Kang, S., Nojima, S., Hori, M., Kikutani, H., et al. (2008). Involvement of Sema4A in the progression of experimental autoimmune myocarditis. FEBS Lett 582, 3935-3940.

McCormick, A.M., and Leipzig, N.D. (2012). Neural regenerative strategies incorporating biomolecular axon guidance signals. Ann Biomed Eng 40, 578-597.

Meda, C., Molla, F., De Pizzol, M., Regano, D., Maione, F., Capano, S., Locati, M., Mantovani, A., Latini, R., Bussolino, F., et al. (2012). Semaphorin $4 \mathrm{~A}$ exerts a proangiogenic effect by enhancing vascular endothelial growth factor-A expression in macrophages. J Immunol 188, 4081-4092.

Miao, H.Q., Soker, S., Feiner, L., Alonso, J.L., Raper, J.A., and Klagsbrun, M. (1999). Neuropilin-1 mediates collapsin-1/semaphorin III inhibition of endothelial cell motility: functional competition of collapsin-1 and vascular endothelial growth factor-165. J Cell Biol 146, 233-242.

Micucci, C., Orciari, S., and Catalano, A. (2010). Semaphorins and their receptors in stem and cancer cells. Curr Med Chem 17, 3462-3475.

Mizui, M., Kumanogoh, A., and Kikutani, H. (2009). Immune semaphorins: novel features of neural guidance molecules. J Clin Immunol 29, 1-11.

Muratori, C., and Tamagnone, L. (2012). Semaphorin signals tweaking the tumor microenvironment. Adv Cancer Res 114, 59-85.

Nkyimbeng-Takwi, E., and Chapoval, S.P. (2011). Biology and function of neuroimmune semaphorins $4 A$ and $4 \mathrm{D}$. Immunol Res 50, 10-21.

Nogi, T., Yasui, N., Mihara, E., Matsunaga, Y., Noda, M., Yamashita, N., Toyofuku, T., Uchiyama, S., Goshima, Y., Kumanogoh, A., et al. (2010). Structural basis for semaphorin signalling through the plexin receptor. Nature 467, 1123-1127.

O'Connor, B.P., Eun, S.Y., Ye, Z., Zozulya, A.L., Lich, J.D., Moore, C.B., locca, H.A., Roney, K.E., Holl, E.K., Wu, Q.P., et al. (2008). Semaphorin $6 D$ regulates the late phase of $C D 4+T$ cell primary immune responses. Proc Natl Acad Sci U S A 105, 13015-13020.

Ohta, K., Mizutani, A., Kawakami, A., Murakami, Y., Kasuya, Y., Takagi, S., Tanaka, H., and Fujisawa, H. (1995). Plexin: a novel neuronal cell surface molecule that mediates cell adhesion via a homophilic binding mechanism in the presence of calcium ions. Neuron 14, 1189-1199.

Ohta, K., Takagi, S., Asou, H., and Fujisawa, H. (1992). Involvement of neuronal cell surface molecule B2 in the formation of retinal plexiform layers. Neuron 9, 151-161.

Oinuma, I., Ishikawa, Y., Katoh, H., and Negishi, M. (2004). The Semaphorin 4D receptor Plexin-B1 is a GTPase activating protein for R-Ras. Science 305, 862-865.

Okuno, T., Nakatsuji, Y., Moriya, M., Takamatsu, H., Nojima, S., Takegahara, N., Toyofuku, T., Nakagawa, Y., Kang, S., Friedel, R.H., et al. (2010). Roles of Sema4D-plexin-B1 interactions in the central nervous system for pathogenesis of experimental autoimmune encephalomyelitis. J Immunol 184, 1499-1506.

Pasterkamp, R.J., and Kolodkin, A.L. (2003). Semaphorin junction: making tracks toward neural connectivity. Curr Opin Neurobiol 13,
79-89.

Perala, N., Sariola, H., and Immonen, T. (2012). More than nervous: the emerging roles of plexins. Differentiation 83, 77-91.

Potiron, V.A., Roche, J., and Drabkin, H.A. (2009). Semaphorins and their receptors in lung cancer. Cancer Lett 273, 1-14.

Rizzolio, S., and Tamagnone, L. (2011). Multifaceted role of neuropilins in cancer. Curr Med Chem 18, 3563-3575.

Rohm, B., Ottemeyer, A., Lohrum, M., and Puschel, A.W. (2000). Plexin/neuropilin complexes mediate repulsion by the axonal guidance signal semaphorin 3A. Mech Dev 93, 95-104.

Roney, K.E., O'Connor, B.P., Wen, H., Holl, E.K., Guthrie, E.H., Davis, B.K., Jones, S.W., Jha, S., Sharek, L., Garcia-Mata, R., et al. (2011). Plexin-B2 negatively regulates macrophage motility, Rac, and Cdc42 activation. PLoS ONE 6, e24795.

Sakurai, A., Doci, C.L., and Gutkind, J.S. (2012). Semaphorin signaling in angiogenesis, lymphangiogenesis and cancer. Cell Res 22, 23-32.

Satoda, M., Takagi, S., Ohta, K., Hirata, T., and Fujisawa, H. (1995). Differential expression of two cell surface proteins, neuropilin and plexin, in Xenopus olfactory axon subclasses. J Neurosci 15, 942-955.

Serini, G., Maione, F., Giraudo, E., and Bussolino, F. (2009). Semaphorins and tumor angiogenesis. Angiogenesis 12, 187-193.

Shi, W., Kumanogoh, A., Watanabe, C., Uchida, J., Wang, X., Yasui, T., Yukawa, K., Ikawa, M., Okabe, M., Parnes, J.R., et al. (2000). The class IV semaphorin CD100 plays nonredundant roles in the immune system: defective $B$ and $T$ cell activation in CD100-deficient mice. Immunity 13, 633-642.

Smith, E.P., Shanks, K., Lipsky, M.M., DeTolla, L.J., Keegan, A.D., and Chapoval, S.P. (2011). Expression of neuroimmune semaphorins $4 A$ and $4 D$ and their receptors in the lung is enhanced by allergen and vascular endothelial growth factor. BMC Immunol 12, 30.

Sperry, R.W. (1963). Chemoaffinity in the orderly growth of nerve fiber patterns and connections, Vol 50.

Suto, F., Tsuboi, M., Kamiya, H., Mizuno, H., Kiyama, Y., Komai, S., Shimizu, M., Sanbo, M., Yagi, T., Hiromi, Y., et al. (2007). Interactions between plexin-A2, plexin-A4, and semaphorin $6 \mathrm{~A}$ control lamina-restricted projection of hippocampal mossy fibers. Neuron 53, 535-547.

Suzuki, K., Okuno, T., Yamamoto, M., Pasterkamp, R.J., Takegahara, N., Takamatsu, H., Kitao, T., Takagi, J., Rennert, P.D., Kolodkin, A.L., et al. (2007). Semaphorin 7A initiates T-cell-mediated inflammatory responses through alpha1beta1 integrin. Nature 446, 680-684.

Takagi, S., Hirata, T., Agata, K., Mochii, M., Eguchi, G., and Fujisawa, H. (1991). The A5 antigen, a candidate for the neuronal recognition molecule, has homologies to complement components and coagulation factors. Neuron 7, 295-307.

Takagi, S., Tsuji, T., Amagai, T., Takamatsu, T., and Fujisawa, H. (1987). Specific cell surface labels in the visual centers of Xenopus laevis tadpole identified using monoclonal antibodies. Dev Biol 122, 90-100.

Takahashi, T., Fournier, A., Nakamura, F., Wang, L.H., Murakami, Y., Kalb, R.G., Fujisawa, H., and Strittmatter, S.M. (1999). Plexin-neuropilin-1 complexes form functional semaphorin-3A receptors. Cell 99, 59-69. 
Takahashi, T., and Strittmatter, S.M. (2001). Plexina1 autoinhibition by the plexin sema domain. Neuron 29, 429-439.

Takamatsu, H., and Kumanogoh, A. (2012). Diverse roles for semaphorin-plexin signaling in the immune system. Trends Immunol 33, 127-135.

Takamatsu, H., Takegahara, N., Nakagawa, Y., Tomura, M., Taniguchi, M., Friedel, R.H., Rayburn, H., Tessier-Lavigne, M., Yoshida, Y., Okuno, T., et al. (2010). Semaphorins guide the entry of dendritic cells into the lymphatics by activating myosin II. Nat Immunol 11, 594-600.

Takegahara, N., Takamatsu, H., Toyofuku, T., Tsujimura, T., Okuno, T., Yukawa, K., Mizui, M., Yamamoto, M., Prasad, D.V., Suzuki, K., et al. (2006). Plexin-A1 and its interaction with DAP12 in immune responses and bone homeostasis. Nat Cell Biol 8, $615-622$.

Tamagnone, L., Artigiani, S., Chen, H., He, Z., Ming, G.I., Song, H., Chedotal, A., Winberg, M.L., Goodman, C.S., Poo, M., et al. (1999). Plexins are a large family of receptors for transmembrane, secreted, and GPI-anchored semaphorins in vertebrates. Cell 99, 71-80.

Tamura, M., Takeyama, Y., Yamamoto, M., Shima, K., Suzuki, K., Nakamura, T., Asano, T., and Yoshida, K. (2008). [A case of pulmonary inflammatory pseudotumor accompanied with increased serum immunoglobulin $G$ levels and autoimmune pancreatitis]. Nihon Kokyuki Gakkai Zasshi 46, 909-914.

Torres-Vazquez, J., Gitler, A.D., Fraser, S.D., Berk, J.D., Van, N.P., Fishman, M.C., Childs, S., Epstein, J.A., and Weinstein, B.M. (2004). Semaphorin-plexin signaling guides patterning of the developing vasculature. Dev Cell 7, 117-123.

Toyofuku, T., Yabuki, M., Kamei, J., Kamei, M., Makino, N., Kumanogoh, A., and Hori, M. (2007). Semaphorin-4A, an activator for T-cell-mediated immunity, suppresses angiogenesis via Plexin-D1. Embo J 26, 1373-1384.

Watarai, H., Sekine, E., Inoue, S., Nakagawa, R., Kaisho, T., and
Taniguchi, M. (2008). PDC-TREM, a plasmacytoid dendritic cell-specific receptor, is responsible for augmented production of type I interferon. Proc Natl Acad Sci U S A 105, 2993-2998.

Wen, H., Lei, Y., Eun, S.Y., and Ting, J.P. (2010). Plexin-A4semaphorin $3 \mathrm{~A}$ signaling is required for Toll-like receptor- and sepsis-induced cytokine storm. J Exp Med 207, 2943-2957.

Winberg, M.L., Noordermeer, J.N., Tamagnone, L., Comoglio, P.M., Spriggs, M.K., Tessier-Lavigne, M., and Goodman, C.S. (1998). Plexin $A$ is a neuronal semaphorin receptor that controls axon guidance. Cell 95, 903-916.

Witherden, D.A., Watanabe, M., Garijo, O., Rieder, S.E., Sarkisyan, G., Cronin, S.J., Verdino, P., Wilson, I.A., Kumanogoh, A., Kikutani, H., et al. (2012). The CD100 Receptor Interacts with Its Plexin B2 Ligand to Regulate Epidermal gammadelta $\mathrm{T}$ Cell Function. Immunity 37, 314-325.

Wong, A.W., Brickey, W.J., Taxman, D.J., van Deventer, H.W., Reed, W., Gao, J.X., Zheng, P., Liu, Y., Li, P., Blum, J.S., et al. (2003). CIITA-regulated plexin-A1 affects T-cell-dendritic cell interactions. Nat Immunol 4, 891-898.

Yaron, A., and Sprinzak, D. (2012). The cis side of juxtacrine signaling: a new role in the development of the nervous system. Trends Neurosci 35, 230-239.

Yoshida, Y. (2012). Semaphorin signaling in vertebrate neural circuit assembly. Front Mol Neurosci 5, 71.

Yoshida, Y., Han, B., Mendelsohn, M., and Jessell, T.M. (2006). PlexinA1 signaling directs the segregation of proprioceptive sensory axons in the developing spinal cord. Neuron 52, 775-788.

Yu, D., Cook, M.C., Shin, D.M., Silva, D.G., Marshall, J., Toellner, K.M., Havran, W.L., Caroni, P., Cooke, M.P., Morse, H.C., et al. (2008). Axon growth and guidance genes identify T-dependent germinal centre B cells. Immunol Cell Biol 86, 3-14.

Zhou, Y., Gunput, R.A., and Pasterkamp, R.J. (2008). Semaphorin signaling: progress made and promises ahead. Trends Biochem Sci 33, 161-170. 